\title{
Botany
}

\section{Surviving or thriving: trade-offs between growth, defense, and reproduction in a native versus in an invasive $R u b u s$}

\begin{tabular}{|c|c|}
\hline Journal: & Botany \\
\hline Manuscript ID & cjb-2020-0233.R2 \\
\hline Manuscript Type: & Article \\
\hline $\begin{array}{r}\text { Date Submitted by the } \\
\text { Author: }\end{array}$ & 28-May-2021 \\
\hline Complete List of Authors: & $\begin{array}{l}\text { Thexton, Brady; Drew University, Environmental Studies and } \\
\text { Sustainability; Georgetown University, Biology } \\
\text { Bajcz, Alex; Drew University, Biology }\end{array}$ \\
\hline Keyword: & $\begin{array}{l}\text { Plant reproduction, Physiological responses, Invasive species, Trade-offs, } \\
\text { Rubus }\end{array}$ \\
\hline $\begin{array}{l}\text { Is the invited manuscript for } \\
\text { consideration in a Special } \\
\text { Issue? : }\end{array}$ & Not applicable (regular submission) \\
\hline
\end{tabular}

\section{SCHOLARONE Manuscripts}


Surviving or thriving: trade-offs between growth, defense, and reproduction in a native versus in an invasive Rubus

\author{
Brady J. Thexton ${ }^{\text {ac* }}$ and Alex W. Bajcz ${ }^{\text {abd }}$ \\ *aProgram of Environmental Studies and Sustainability, Drew University. Madison, NJ, USA \\ 07940.bthexton@drew.edu \\ bDepartment of Biology, Drew University. Madison, NJ, USA 07940. abajcz@drew.edu \\ 'Department of Biology, Georgetown University. Washington, D.C., USA 20007. \\ bt495@georgetown.edu \\ dDepartment of Fisheries, Wildlife, and Conservation Biology, College of Food, Agricultural, \\ and Natural Resource Sciences, University of Minnesota-Twin Cities Campus. St. Paul, MN, \\ USA 55108. \\ * Corresponding author
}

Competing interests: The authors declare there are no competing interests. 


\begin{abstract}
Little is known about limits to reproduction in plants, especially as to how their other life history functions (growth and defense) may constrain reproductive investment. Understanding these constraints can help researchers refine best practices for cultivating species like Rubus (Family: Rosaceae) that produce nutritious fruits as well as controlling invasive species. Here, we sought to elucidate potential trade-offs between growth, defense, and reproduction in native Rubus allegheniensis (common blackberry) and invasive $R$. phoenicolasius (wineberry) while accounting for the effects of varying insect herbivory and resource availability levels. We observed traits related to physical defense (e.g., prickle intensity), growth (e.g., cane length), and floral reproduction (e.g., ripe fruits) as well as carbon availability (e.g., canopy cover). We then used multiple regressions to characterize relationships between these variables for both species. We found potential evidence for two induced defenses in the invasive wineberry. Also, five models returned significant results indicative of trade-offs between reproduction and growth, reproduction and defense, and defense and growth in one or both species. Our results highlight the importance of understanding the defensive strategies utilized by these species because inducible defenses may result in trade-offs that could reduce yields and also increase the invasive potential of Rubus species.
\end{abstract}

Key words: Rubus $\bullet$ Trade-offs $\bullet$ Plant reproduction $\bullet$ Physiological responses $\bullet$ Invasive species 


\section{Introduction}

Ecological success is often treated as synonymous with Darwinian fitness - surviving long enough to pass on one's genes at higher rates than rivals (Pough 1989; Demetrius and Ziehe 2007; Lailvaux and Husak 2014). To succeed, then, requires balancing several life history functions, each corresponding to a suite of traits (Lovett Doust 1989, Obeso 2002). These functions are: 1) growth—building structures to acquire resources and outcompete rivals for resource access (e.g., generating leaves and roots) as well as to achieve a functional size and shape; 2) "maintenance"_-development of physical and/or chemical elements for protection from (a)biotic stressors, storing excess resources to persist through adverse conditions, and repairing damaged or aging systems; and 3) reproduction - the passing on of genes to future generations. Balancing these functions, however, is no easy task. Physiological trade-offsnegative correlations between the expression levels of physical traits (as defined by Obeso 2002) — between life history-linked traits are assumed to be inevitable because, in every system, resources are finite and thus every organism must allocate its limited resources to some life history functions over others, even when investing in all of them would theoretically be better (Obeso 2002). In longer-lived species, these trade-offs — and their intersections with herbivoryare not well documented.

Of particular interest with respect to longer-lived plant species are the defensive strategies employed by the plant as well as the physiological trade-offs between and within the life history functions during reproductive bouts (Obeso 2002). Defensive investment helps ensure survival to reproductive age despite antagonistic relationships (e.g., herbivory) and/or detrimental abiotic processes (e.g., extreme weather). Plants are thought to display three general defensive strategies: little to no defense (Strauss and Agrawal 1999), primarily inducible 
defenses, and primarily constitutive defenses (Karban and Baldwin 1997). Ito and Sakai (2009) modeled environmental conditions that might select for an ideal strategy. They concluded little to no defense would be optimal when biomass lost to herbivory and the probability of herbivory were both low on average, constitutive defenses would be optimal when biomass lost and probability of herbivory were both high, and induced defenses would be optimal in moderate situations. In our study, we focused on the trade-offs between physical defenses, growth, and floral reproduction (as opposed to asexual reproduction) that are evident once any effects of herbivory are accounted for. Because these functions are resource-demanding, trade-offs between - and even within — them should be readily observable (Obeso 2002). We also assume that species evolve life history strategies that optimize investment between these functions, revealing the priorities of that particular species in terms of achieving fitness in their typical habitats (Obeso 2002).

Our research had two primary goals, and we chose two species in the Rubus genus (Family: Rosaceae), one native and one invasive within our study region, to explore these. First, we sought to document if and how physical defense, growth, and floral reproduction trade off in these species. We chose to focus on carbon-demanding traits related to the three life history functions because carbon's availability can be easily and reliably inferred using field data. Second, we sought to document how herbivory may affect the physical defense, growth, and floral reproduction of the native and invasive Rubus because herbivory-induced changes could intensify some trade-offs and obscure others. We assumed both growth and reproduction would be negatively impacted by herbivory because of lost resources and an increased need for defensive investment (Herms and Mattson 1992; Massan 2013). We know Rubus have many constitutive physical defenses (Graham and Brennan 2018). We predicted that overall investment 
to physical defenses may be limited in the invasive species given the likelihood that it might lack naturalized herbivores in the introduced range as proposed by the enemy release hypothesis (Keane and Crawley 2002, Colautti et al. 2004, Williams and Sahli 2016). The "evolution of increased competitive ability" (EICA) hypothesis and the shifting defense hypothesis additionally posit that invasive species may evolve to be more competitive (perhaps by suffering less severe trade-offs) and/or might prioritize more measured and less expensive defenses within their novel ranges than they otherwise might or than their competitors must (Blossey and Nötzold 1995, Joshi and Vrieling 2005). We predicted the following: 1) Increased relative carbon investment to defense would result in decreased reproductive carbon allocation; 2) Growth-related and defensive traits would display carbon-allocation trade-offs; 3 ) Carbon allocation to growth occurring concurrently with reproduction would coincide with decreased reproductive carbon allocation; 4) Trade-offs might occur within life history functions, especially between defensive traits (Björkman and Anderson 1990); and 5) The native and invasive species would both display trade-offs, but these would be reduced in number, severity, or both in the invasive species, and herbivory might have less severe an impact on wineberry's reproductive effort.

\section{Methods}

Study species

In this study, we observed two Rubus species: the native Allegheny blackberry $(R$. allegheniensis) and the invasive Japanese wineberry (R. phoenicolasius; native to East Asia). We chose Rubus species for the following reasons: they possess several readily measurable traits mappable to particular life history functions; they are semi-long-lived perennials whose trade- 
offs are not already well-documented; they display prominent constitutive physical defenses (among these prickles, hairs, and trichomes); and the genus contains hundreds of species all thought to produce edible, nutritious fruits (Beattie et al. 2005, Nile and Park 2014) that have considerable use potential for humans (Tontisirin et al. 2002; Müller and Krawinkel 2005; Tulchinsky 2010). As such, it may be particularly forward-looking to better understand this genus' reproductive limitations and behaviors.

Virtually all Rubus produce biennial canes — upright stems possessing vascular tissue, wood, and leaves (Graham and Brennan 2018). Both blackberry and wineberry are woody shrubs with similar life histories and physiologies, even though recent research suggests they are only distantly related (Carter et al. 2019). The diagnostic features for identification for both species are shown in Figure 1. Rubus reproduce sexually via flowers but also asexually via several means including tip-rooting, self-fertilization, and apomixis (Graham and Brennan 2018). Rubus produce aggregates of drupelets, the whole of which is considered the functional "fruit" of dispersal. Here, we focus only on reproduction via flowers, which is likely a mix of sexual and asexual reproduction through apomixes and self-pollination. We also focus only on second-year, reproductive canes (floricanes), which produce fruits and seeds via open pollination, whereas first-year canes heavily focus on growth and maintenance functions instead.

Multiple studies have been performed on other Rubus species; these have identified several potential trade-offs (Björkman and Anderson 1990, Gibson et al. 1993, McDowell and Turner 2002). However, each of these studies focused on only one or two trait pairings in one or two species, however, preventing a fuller characterization of these species' (and thus the genus') reproductive limitations and behaviors. 


\section{Plot set-up}

We established 49 plots across ten properties around northcentral New Jersey, USA (Fig $\mathrm{S} 1)$. Plots were approximately elliptical with an average area of $91.34 \mathrm{~m}^{2}\left(\mathrm{~min}\right.$ and $\max : 26.67 \mathrm{~m}^{2}$ and $312.87 \mathrm{~m}^{2}$ ). The region is classified as temperate forest, and most plots were located near hiking trails. Field data were collected from May $27^{\text {th }}$ to August $7^{\text {th }}, 2019$.

To be considered a study plot, there needed to be $40+$ floricanes present from at least one of the study species. No plots found that met this criterion were dismissed unless they were within 50 meters of another plot that shared a species so as to increase plot diversity. We labeled the species with the highest floricane number the dominant species at each plot. If the other species was also present and had at least 20 floricanes, we labelled it as subdominant. We then chose twelve canes of the dominant species randomly (by blindly tossing objects) or systematically (selecting every $\mathrm{n}^{\text {th }}$ cane encountered during a random walk). The former approach was used unless a plot was overgrown, making the systematic approach the only feasible way to select canes. If a subdominant species was present, we selected six study canes using the same methods. We marked chosen canes with color-coded pipe cleaners, which are easy to see but are unlikely to physically damage plants.

\section{Quantifying carbon availability and herbivory}

Two research objectives were to characterize the carbon availability and herbivory levels at each plot. Plants acquire carbon via photosynthesis, and the rate of photosynthesis is generally positively correlated with available light; however, measuring light quickly but meaningfully under field conditions can be difficult. As such, we took two measurements of light for each plot. First, we obtained an estimate of maximum light availability by measuring photosynthetically 
active radiation (PAR) at each plot center using a LI-COR LI-250A light meter. We took these measurements between June $11^{\text {th }}$ and July $30^{\text {th }}, 2019$ during mid-day (10:30AM to $\left.3: 30 \mathrm{PM}\right)$ whenever possible and on at least three separate days per plot. Cloud cover conditions were noted during these measurements. Then, we selected the maximum value of our readings for each plot for use in our analyses. We also calculated the percent canopy cover for each plot using the smartphone application CanopyApp (University of New Hampshire, version 1.0.3) between June $11^{\text {th }}$ and June $22^{\text {nd }}, 2019$. We first took pictures of the canopy above each plot center on a clear, sunny day. The app's software was then used to isolate and then calculate the pixel percentage of structures intercepting light that would otherwise reach the forest floor (Fig. 2a). We then converted percent canopy cover data to percent light transmittance $(100 \%$ - percent canopy cover $=$ percent light transmittance). We correlated these two proxies of carbon availability and found a strong, positive relationship $(\mathrm{r}=0.50)$. As such, we decided to use just one of these (light transmittance) for our analyses.

To approximate leaf-level chewing herbivory by insects (hereafter referred to as leaflevel herbivory) at each plot, we calculated average percent leaf area loss via the smartphone application Leaf Area (Adam Campbell, version 1.1.0). The leaves measured, which were those growing furthest from the ground and corresponding to those toward the middle of the cane (rather than the youngest or oldest leaves), were cut from unmarked canes growing immediately next to marked canes to prevent damage to canes under study. Visual inspections indicated that levels of herbivory experienced by leaves in the middle of the canes was broadly similar to those in other locations on the plant. The selected canes were dispersed evenly throughout the plot to account for within-plot variability in herbivory damage. We measured six leaves of the dominant species and three leaves of the subdominant species at each plot. Following the application's 
instructions, we drew four black dots on white paper in a $10 \mathrm{~cm} \times 10 \mathrm{~cm}$ square. We then placed each leaf within the square and used Plexiglas to hold it in place and to flatten it. A photo was taken, and the app was used to increase the contrast until only the leaf and any missing leaf area were visible (Fig. 2b). We then used the app's drawing tool to fill in missing leaf edges. The app then calculated total leaf area, total area missing, and percent leaf loss.

\section{Defense traits}

To characterize physical defense allocation, we quantified prickle length, prickle density, leaf toughness, and stem basal diameter. We argue stem basal diameter is a defensive feature because thicker stems may deter passage through a stand by large mammals as well as prevent breakage during contact or extreme weather. While it is also related to growth, we felt basal diameter was less indicative of growth investment and more indicative of defensive investment than cane length because canes needn't be thick to also be long, but a thick cane is much less likely to break if flexed than a thin one. At season's end, we cut and harvested subsections of marked canes spanning from the root collar up to the fourth visible node. We also haphazardly harvested three fully emerged leaves from each cane (one representative, undamaged leaf from the base, middle, and tip of each cane). Both stem segments and leaves were stored in a $-20^{\circ} \mathrm{C}$ freezer for later analyses.

We measured prickle density by first identifying the three nodes closest to the root collar. The number of prickles plus prickle scars between the first and second and second and third nodes were counted, and the internodal lengths were measured (in $\mathrm{cm}$ ). We averaged these data to yield mean prickle density (prickles per $\mathrm{cm}$ ) for each cane. To obtain prickle lengths, up to five equally dispersed intact prickles were selected from each segment and measured (in mm). 
These lengths were averaged to yield a mean prickle length for each cane. We then calculated prickle intensity (in $\mathrm{mm} \times$ prickles per $\mathrm{cm}$ ) by multiplying average prickle length and prickle density for each plot; this metric was used as a measure of total carbon investment to pricklebased defenses.

We measured leaf toughness similar to Lowman (1984) and Feeny (1970). We constructed an apparatus out of wood blocks and metal dowels (Fig. S2). We pressed the center leaflet from a randomly selected leaf from each cane between the apparatus' two halves, taking care not to place the midvein over the central hole. We then placed the metal plunger in the top of the central hole down to the leaflet surface. We placed an empty beaker on the plunger and slowly filled it with sand until the plunger dowel punctured the leaflet. Three beakers $(50 \mathrm{~mL}$, $100 \mathrm{~L}, 250 \mathrm{~mL}$ ) were used to ensure a wide range of leaves could be measured because larger beakers alone could puncture weaker leaflets. The combined beaker, sand, and tape roll (used to increase beaker stability) mass required to break the leaflet was recorded as leaf toughness (in $\mathrm{g}$ of total mass). The mass of the plunger was assumed to be constant and was not included.

We measured the basal diameter of each cane segment (in $\mathrm{mm}$ ) immediately following harvest using digital calipers (Precision Measuring Digital Caliper 150mm).

\section{Floral reproductive traits}

We measured carbon allocation to floral reproduction via measurement of flower number, ripe fruit number, fruit set, and fruit dry:wet mass ratio for each plot and cane. We first counted all flowers on marked canes in early June 2019. We later collected ripe fruit in three rounds for both species, each round taking place one week apart from late June to early August 2019. In each round, we harvested all visibly ripe fruits from marked canes and placed them in labelled 
plastic sandwich bags. A fruit was considered ripe based on coloration; we considered blackberry fruits ripe if a majority of drupelets were black and wineberry fruits ripe if a majority of drupelets were deep red. All fruits were stored in a $-20^{\circ} \mathrm{C}$ freezer for later analyses.

To estimate the fruit dry:wet mass ratio, we took a $4 \mathrm{~g}$ sub-sample of ripe fruits collected from each plot-species combination and placed them in a $70^{\circ} \mathrm{C}$ drying oven for $48 \mathrm{hrs}$. We then reweighed the dried fruits and divided the dry mass by the fresh mass. Higher values of this measure indicate a relatively greater investment to the carbon-containing portion of fruits (seeds, pulp, rind, sugars, etc.) irrespective of fruit size, mass, or number (Stapanian 1982).

\section{Growth traits}

We considered cane length and average per-leaf area measures of carbon allocation to growth. At season's end, we cut marked canes and measured the length of each (in $\mathrm{cm}$ ) using a measuring tape. If the cane was tip-rooted, we cut the tip as close to the ground as possible. If the cane was branched (uncommon but not rare), we measured only the longest branch, so our values will be underestimates. We calculated average leaf size by averaging the total leaf area measurements provided by Leaf Area as previously described for each cane.

We examined multiple defensive, reproductive, and growth-related traits to assess for trade-offs within life history functions; focusing on only one or a few traits when within-function trade-offs might exist can lead to mischaracterization of total resource investment to individual functions as well as of the number and severity of trade-offs (Mole 1994; Koricheva 2002; Barton and Koricheva 2010). Within each life history function, resources may need to be finely allocated between multiple related but exclusive traits if resources are sufficiently scarce. By only measuring one trait per life history function, the chances increase of missing key trade-offs. 


\section{Statistical analyses}

We used RStudio (version 1.1.463; R Core Team 2019) for statistical analyses. Graphics were produced using ggplot2 (Wickham 2009). We used multiple regressions ( $g l m$ function) to assess for meaningful effects of herbivory on carbon investment toward growth-related, reproductive, and defensive traits. All data were averaged to plot for each species to account for pseudo-replication; Rubus are commonly clonal and thus it must be assumed that most individuals of the same species in a plot are very close relatives without doing genotypic analyses (Nybom \& Schaal 1990). The basic model structure was:

$$
y=\beta_{0}+\beta_{1} x_{1}+\beta_{2} x_{2}+\beta_{3} x_{3}+\beta_{4} x_{1} x_{3}
$$

where $\mathrm{y}$ is a measure of carbon allocation (to defense, growth, or reproduction), $x_{1}$ is the average percent leaf loss (a measure of leaf-level herbivory and the term of interest), $x_{2}$ is canopy light transmittance (a proxy for carbon availability), and $x_{3}$ is species (coded blackberry $=0$ and wineberry $=1$ ). The $\beta$ s are regression coefficients to be estimated by the model. We included an interaction term between percent leaf loss and species $\left(x_{1} x_{3}\right)$ because we assumed the two species might respond differently to herbivory, in part because blackberry is native and wineberry is invasive and may experience different herbivory pressures. A significant $\beta_{4}$ value would indicate how much the $\beta_{1}$ value (the slope between herbivory and the dependent variable) would change for wineberry versus the default blackberry. Canopy light transmittance $\left(x_{3}\right)$ was included because we assumed plants receiving more light would have higher y values because they have more carbon to invest, irrespective of any negative impacts herbivory may otherwise have had; this term would help to control for any such effect. The y variables used in this set of 
models were flower number, ripe fruit number, fruit set, fruit dry:wet mass ratio, leaf toughness, prickle intensity, and average per-leaf size. Percent leaf loss was the only $x_{1}$ variable.

We also used multiple linear regression models to assess for negative relationships between growth-related, defensive, and reproductive traits that could reflect potential physiological trade-offs. All data were averaged to plot for each species to eliminate possible pseudo-replication. The structure for these models was:

$$
y=\beta_{0}+\beta_{1} x_{1}+\beta_{2} x_{2}+\beta_{3} x_{3}+\beta_{4} x_{4}+\beta_{5} x_{1} x_{4}
$$

where $\mathrm{y}$ is a carbon allocation measure (to defense, growth, or reproduction), $x_{1}$ is a measure of carbon allocation that occurs prior to or concomitant with that for $y$ (this is the term of interest), $x_{2}$ is cane length (a measure of investment towards growth in the cane's first, non-reproductive year), $x_{3}$ is canopy light transmittance, and $x_{4}$ is species. The interaction between species and the measure of carbon allocation $\left(x_{1} x_{4}\right)$ was included in these models because we assumed the two species may allocate resources between life history traits differently. The canopy light transmittance term $\left(x_{3}\right)$ was included in these models because we wanted to account for any enhancement effect of greater light availability on y values irrespective of potential trade-offs. Similarly, the cane length term $\left(x_{2}\right)$ was included because we assumed longer canes would have higher y values because of greater capacity for carbon uptake due to increased numbers of nodes and leaves, irrespective of any trade-offs. In these models, evidence of a trade-off would be a negative $\beta_{1}$. A significant $\beta_{5}$ would indicate the species display different relationships between $x_{1}$ and y (e.g., one species displays a trade-off and the other does not; Fig. 3a-c). The response variables $(\mathrm{y})$ considered for these models were flower number, ripe fruit number, fruit set, fruit dry:wet mass ratio, leaf toughness, prickle intensity, and average per-leaf size. The measures of carbon allocation $\left(x_{1}\right)$ considered were average leaf size, cane length, stem basal diameter, leaf 
toughness, and prickle intensity. Several combinations were not considered because they would have included identical traits (e.g., average leaf size versus itself), been redundant (e.g., average leaf size and leaf toughness were both possible $x_{1}$ and y variables), or been temporally illogical (having a y variable whose investment occurs prior to that of the $x_{1}$ variable). When cane length was the measure of carbon allocation $\left(x_{1}\right)$, the cane length $\left(x_{2}\right)$ term was dropped.

We initially ran all models with the interaction terms described above. However, whenever the interaction term was insignificant (prior to any correction, see below), it was removed and the model re-ran to reduce model complexity. No other covariates were removed from the models in this way. We also included weights in all models; double the weight was given to plots containing twelve canes of a species relative to plots containing six canes. For all models, we ensured residuals were normally and identically distributed using Q-Q plots and other instruments. When these assumptions were violated, the model was re-run as a Poisson regression (which yields unbiased, approximate coefficient estimates for non-discrete, positive data). Only final model results are presented. We adjusted our p-values using the false discovery rate $($ function $=p$.adjust $)$ and results were deemed significant when $p<0.05$ and marginally significant when $0.05<p<0.10$.

\section{Results}

\section{Variability between species}

Investment toward reproductive, defensive, and growth-related traits differed notably between $R$. allegheniensis and $R$. phoenicolasius (Tables $1, \mathrm{~S} 1$ ). In general, blackberry displayed higher variability compared to wineberry for many but not all traits. Average values for some traits (flower number, stem basal diameter, leaf toughness, and average leaf size) were higher for 
blackberry than wineberry, but, for other traits (ripe fruit number, fruit set, prickle intensity, and cane length), the opposite was true. The range of environments inhabited by the species also differed, with both canopy light transmittance and percent leaf loss being higher on average but also more variable across blackberry plots than wineberry plots (Tables $1, \mathrm{~S} 1$ ).

\section{Effects of herbivory}

The data showed two instances where reproductive traits could be expected to significantly decrease as rates of leaf-level herbivory increase for both wineberry and blackberry. Ripe fruit number is expected to change in blackberry by a factor of 0.85 with every $1 \%$ increase in percent leaf loss $\left(\beta_{\text {MAIN EFFECT }}=-0.16\right.$; Table 2$)$. In wineberry, ripe fruit number is predicted to change by a factor of 0.95 instead with every $1 \%$ increase in percent leaf loss $\left(\beta_{\text {INTERACTION TERM }}\right.$ $=0.11$ ). However, wineberry's ripe fruit number is expected to be 2.36 times greater than blackberry's, all else being equal $\left(\beta_{\text {SPECIES }}=0.86\right.$; Table 2$)$. Fruit set is predicted to significantly decrease in both species by 0.011 with every $1 \%$ increase in leaf loss $\left(\beta_{\text {MAIN EFFECT }}\right.$ $=-0.011$; Table 2), but wineberry's fruit set is expected to be higher than blackberry's by 0.10 under identical circumstances $\left(\beta_{\text {SPECIES }}=0.10\right.$; Table 2$)$. To put these results in context, average fruit set ranged from 0 to 0.35 in blackberry and from 0.016 to 0.50 in wineberry (Table S1), while average leaf area loss ranged from $0.10 \%$ to $11.3 \%$ in blackberry and from $0.001 \%$ to $13.9 \%$ in wineberry (Table S1). As such, fruit set values in plots with the highest observed herbivory levels would be expected to be 0.12 (34\% of the maximum value) lower in blackberry and $0.15(30 \%$ of the maximum value) lower in wineberry on average than in plots with the least amount of observed herbivory. 
Our analyses indicated one potential instance where a defensive trait was expected to increase as rates of leaf-level herbivory increase for both wineberry and blackberry, although this trend lost marginal significance after adjusting our $p$ values. Prickle intensity was predicted to increase by $0.149 \mathrm{~mm} \times$ prickles per $\mathrm{cm}$ with every $1 \%$ increase in percent leaf loss for both species $\left(\beta_{\text {MAIN EFFECT }}=0.149\right.$, adjusted $p=0.117$; Table 2$)$. However, wineberry's prickle intensity is predicted to be significantly greater than blackberry's by $2.66 \mathrm{~mm} \times$ prickles per $\mathrm{cm}$ under identical circumstances $\left(\beta_{\text {SPECIES }}=2.66\right.$; Table 2$)$.

Our data indicated three additional traits—one each reproductive, growth-related, and defensive - are predicted to decrease with increasing leaf-level herbivory rates for blackberry but not for wineberry. With every $1 \%$ increase in leaf loss, blackberry flower number is expected to change by a factor of $0.948\left(\beta_{\text {MAIN EFFECT }}=-0.0536\right)$, average leaf size by a factor of 0.969 $\left(\beta_{\text {MAIN EFFECT }}=-0.0313\right)$, and leaf toughness by a factor of $0.978\left(\beta_{\text {MAIN EFFECT }}=-0.0227\right.$; Table 2). These same three traits also showed significant relationships with percent leaf loss in wineberry, but these relationships were instead positive. For every $1 \%$ increase in leaf loss, wineberry flower number is expected to change by a factor of $1.031\left(\beta_{\text {INTERACTION TERM }}=\right.$ $0.0839)$, average per-leaf size by a factor of $1.035\left(\beta_{\text {INTERACTION TERM }}=0.0662\right)$, and leaf toughness by a factor of $1.016\left(\beta_{\text {INTERACTION TERM }}=0.0382\right.$; Table 2$)$. All other models were nonsignificant (Table 2).

\section{Trade-offs}

We detected evidence of three potential trade-offs occurring in both Rubus species, one each between reproduction and growth, reproduction and defense, and growth and defense. Fruit number is predicted to change by a factor of 0.980 with every $1 \mathrm{~cm}^{2}$ increase in average per-leaf 
size for both species $\left(\beta_{\text {MAIN EFFECT }}=-0.020\right.$; Table 3; Fig. 3b). However, the number of ripe fruits is expected to be 2.16 times greater in wineberry than in blackberry, all else being equal ( $\beta_{\text {SPECIES }}$ $=0.77$; Table 3 ). For every 1 unit increase in prickle intensity, ripe fruit number is expected to change by a factor of 0.905 for both species $\left(\beta_{\text {MAIN EFFECT }}=-0.10\right.$; Table 3$)$, but wineberry's ripe fruit numbers were predicted to be 2.12 times greater than blackberry's under identical circumstances $\left(\beta_{\text {SPECIES }}=0.75\right)$. Lastly, average leaf size is predicted to change by a factor of 0.946 in blackberry $\left(\beta_{\text {MAIN EFFECT }}=-0.055\right)$ and by a factor of 0.975 in wineberry with every 1 unit increase in prickle intensity $\left(\beta_{\text {INTERACTION TERM }}=0.030\right.$; Table 3; Fig. $\left.3 c\right)$. Wineberry's average leaf size is predicted to be 0.779 times smaller than blackberry's under identical circumstances $\left(\beta_{\text {SPECIES }}=-0.25 ;\right.$ Table 3$)$.

Our models also indicated two additional potential trade-offs for blackberry but not for wineberry. First, flower number is expected to decrease by a factor of 0.997 with each unit increase in leaf toughness $\left(\beta_{\text {MAIN EFFECT }}=-0.00254\right.$; Table 3$)$. To put this result in context, the minimum and maximum values of leaf toughness in blackberry were $116.1 \mathrm{~g}$ and $307 \mathrm{~g}$ (Table 1). This means a plot with the toughest observed leaves would be expected to produce $57.3 \%$ fewer flowers than one with the weakest observed leaves. Second, the fruit dry:wet mass ratio is expected to decrease by 0.00047 with every $1 \mathrm{~cm}^{2}$ increase in average leaf size $\left(\beta_{\mathrm{MAIN} \text { EFFECT }}=\right.$ 4.7x10-4; Table 3; Fig. 3a). This metric ranged from 0.11 to 0.20 for blackberry, and average leaf sizes ranged from $24.83 \mathrm{~cm}^{2}$ to $123.2 \mathrm{~cm}^{2}$ (Table 1). As such, the plot with the largest observed leaves would be expected to produce fruit with a proportional dry mass $0.046(23 \%$ of the maximum observed value) lower on average than the plot with the smallest observed leaves.

Eight regression models returned significant results indicating a positive relationship between our $x_{1}$ and y variables for both species. Six others indicated significant positive 
relationships between variables for one species and no or a negative relationship for the other species. Positive and non-significant relationships are not indicative of trade-offs; as such, they will not be discussed here. All other models $(n=12)$ in this set did not return a significant $p$ value for the independent variable of interest for either species (all respective $p$ values $>0.1$; Table 3).

\section{Discussion}

Our research was driven by the following questions: 1) Are there any trade-offs between growth, reproduction, and defense in our study species? 2) Do these species experience similar life history trade-offs to one another? and 3) How does herbivory affect growth, reproduction, and defense in these species? Our data indicate several potential induced defense responses as well as several potential trade-offs between the three life history functions for both species. However, our data did not indicate any trade-offs within a life history function, although we also did not consider a large number of these $(n=4)$. Lastly, we observed evidence blackberry and wineberry both experience trade-offs but that these might be less severe and less numerous in the invasive wineberry, which may partially explain wineberry's success as an invasive species in New Jersey and have implications for its control.

The variability data we obtained suggest one reason wineberry may be successful as an invasive species in New Jersey. On average, wineberry plots received less light (and thus theoretically have less available carbon) than blackberry plots (32.4\% vs. $45.7 \%$ canopy light transmittance; Table 1). Despite this, wineberry plots, on average, produced more ripe fruits (6.6 vs. 3.5; Table 1) more efficiently (as measured by fruit set; 0.17 vs. 0.062 ; Table 1 ) via longer canes $(140 \mathrm{~cm}$ vs. $130 \mathrm{~cm}$; Table 1$)$ than blackberry plots. These data suggest wineberry is able to 
perform more growth and reproduce more effectively despite fewer available resources than blackberry. One possible explanation for how this is possible could be that wineberry is receiving less average leaf-level herbivory and, as a consequence, needs to invest less carbon into producing tougher leaves and other defenses than blackberry.

The observed decreases in ripe fruit number and fruit set for both species as plots experienced higher herbivory rates were not surprising because leaf-level herbivory commonly decreases reproductive output, in part by eliminating photosynthetic tissues as well as reducing carbon acquisition rates (Massad 2013). That the native species, blackberry, experienced a larger decrease in ripe fruit number with increasing rates of herbivory than wineberry is consistent with results presented by McDowell and Turner (2002). They found the invasive $R$. discolor in the Northwestern USA had greater reproductive success than the native $R$. ursinus. $R$. ursinus produced, on average, many fewer fruit $(23.5 \pm 4.4$ vs. $720.3 \pm 123.9 ; p<0.001)$, with less combined fruit and flower biomass relative to plant size $\left(0.22 \pm 0.03 \mathrm{~g} \mathrm{~g}^{-1}\right.$ vs. $0.36 \pm 0.02 \mathrm{~g} \mathrm{~g}^{-1} ; p$ $=0.01)$, than $\operatorname{did} R$. discolor. They contended these differences were due to $R$. discolor being able to invest relatively more resources to reproduction and relatively less to growth and defense than $R$. ursinus. If our two species exhibit a similar relationship, this could explain why blackberry's reproductive output is predicted to decrease more in circumstances where increased growth (to regrow lost tissue) and defense (to prevent more tissue loss) are required (15\% decrease in ripe fruit number for blackberry vs. 5\% decrease for wineberry per percent increase in percent leaf loss. For example, the predicted decrease in flower number as herbivory increases in blackberry but not wineberry supports the hypothesis that blackberry's reproductive output is more limited by a need to allocate to growth or defense than wineberry's is.

Observing higher prickle intensities for both blackberry and wineberry when leaf-level 
herbivory rates were higher, albeit narrowly insignificant following $p$ value correction, was more unexpected. These results suggest prickles may be limitedly inducible when an individual is subjected to higher levels of herbivory. This possibility is supported by data presented by Bazely et al. (1991). In that study, R. fruticosus displayed increased prickle density (prickles per internode) as simulated browsing increased $(p<0.05)$. However, Gibson et al. (1993) found that simulated browsing on $R$. vestitus did not significantly increase prickle density (prickles per internode; $p>0.05)$. Given that our data were gathered from an uncontrolled, non-experimental study and other studies have found conflicting results, we suggest the extent to which prickles are produced "on demand" may differ across this genus and that experimentation may be required to resolve whether prickles can be induced.

It's worth noting prickles primarily limit browsing by larger mammals, not insects, so an increase in prickle intensity following increased leaf-level herbivory is curious. We did not measure large-mammal herbivory at our plots, but others have previously observed that large mammals frequently browse Rubus (Bazely et al. 1991, Gibson et al. 1993). We cannot dismiss the possibility that large-scale herbivory was occurring in our plots nor that it was correlated (positively or negative) with small-scale herbivory. However, it's reasonable to assume increased prickle production could be a general response to biotic leaf damage of any kind and is primarily aimed at deterring larger herbivores and is less adaptive for insect herbivory specifically. We did not quantify investment to hairs and trichomes, structures more geared toward discouraging insects, so it's plausible we missed an opportunity to document another, more appropriately matched induced response to herbivory occurring within our plots and instead observed only a "mismatched" response.

It's also possible higher herbivory rates in better-defended plots (i.e., plots with more 
prickles) could actually be the result of increased investment in defensive structures. Prickles primarily defend against larger herbivores. If these are no longer visiting plots that are welldefended via prickles, insect herbivores may preferentially seek refuge in these plots due to decreased predation and competition pressures. Another possibility is that insect herbivores may sense prickle intensity as a proxy for plant nutritional value - a well-defended plant could be more nutritious than a less-defended one. Because prickles do not defend against insect herbivores, insects can still eat plants heavily defended with them. We suggest that future studies explore how prickle intensity and insect herbivory rates could be causally related in these species.

A positive relationship between leaf toughness and leaf-level herbivory was also predicted by our models, but for wineberry only. The potential that both tougher leaves and prickles could be inducible to some degree in wineberry suggests this species may be able to initially invest fewer resources to defense and only invest more when a demonstrated need arises (or, alternatively, when prior experience in a habitat indicates a likely need), similar to the apparent behaviors of the invasive $R$. discolor (McDowell and Turner 2002). This could be consistent with the shifting defense hypothesis, which posits that invasive species will undergo shifts in their defensive strategies in their novel ranges due to the lack of specialized herbivores (Joshi and Vrieling 2005). This more economical allocation strategy of carbon to defense may explain how wineberry is able to skirt trade-offs between defense and other life history traits more so than blackberry can, which may help to explain its invasive success here in New Jersey.

Williams and Sahli (2016) found, in their Pennsylvania study, wineberry received half the leaf-level herbivory than its native congener, black raspberry $(R$. occidentalis; $p<0.001)$. Our data corroborate this finding; in our plots, wineberry received, on average, $40 \%$ less leaf-level 
herbivory than blackberry (Table 1). This is not surprising because many native insects may not yet be adapted to feed on it, consistent with the enemy release hypothesis (Colautti et al. 2004). The growing conditions experienced by wineberry in our study region-moderate leaf area loss plus infrequent herbivory — are thought to be optimal for induced rather than constitutive defenses (Ito and Sakai 2002) and may also help explain why wineberry could have more of a tendency to rely on inducible defenses than the native blackberry.

Five models returned significant results consistent with carbon trade-offs between life history functions for at least one species. Two were between reproductive and growth-related traits, two between reproductive and defensive traits, and one between defensive and growthrelated traits. Notably, while two of these occurred in blackberry only, three of them occurred in both species, suggesting the two may be broadly similar in the trade-offs they experience. These results suggest that, overall, these species have evolved to have relatively few trade-offs compared to the number possible, most likely by developing optimized allocation strategies that rarely result in two essential functions strongly demanding the same limited resource simultaneously. However, it also demonstrates that these trade-offs cannot be entirely eliminated because some concurrent investment is unavoidable and resources are finite, as life history theory would predict (Obeso 2002).

Trade-offs we found between growth and either reproduction or defense all included average leaf size as the growth trait while our other growth measure (cane length) was not involved in any trade-offs. This may be explained, as noted by McDowell and Turner (2002), by the fact that reproduction is more likely to experience tension with concurrent rather than prior growth in perennial plants. The leaves we measured were all produced during the same year as the reproductive structures we measured whereas cane length would represent the prior year's 
growth instead. That said, first-year leaf growth rather than stem growth could, to some extent, have limited stored carbon available for later reproduction, but we did not measure first-year leaf growth in our study to assess for this possibility. A trade-off between cane growth and prickle production has been previously documented in R. vestitus (Gibson et al. 1993), but we were unable to find something similar in our study. Because we were unable to measure first-year growth rates for our marked canes, we are unable to say whether this trait could also have traded off with prickle production in our two species or influenced our observed trade-off between second-year leaf production and prickle production. We did, however, measure cane length, which is a reasonable proxy for cane growth rate, and this did not return any such prospective trade-offs.

That said, the apparent trade-off between average leaf size and prickle intensity could instead be due to an increased allocation to prickles in the first year, limiting allocation of carbon to storage for subsequent investment into leaves in the second year. It's possible wineberry and blackberry could both have a default strategy of relatively low first-year prickle investment in order to increase stored carbon supplies and maintain a higher second-year leaf growth rate. This would only be plausible if previously stored carbon is essential for second-year leaves and that a prickle-vs.-storage trade-off in the first year would be significant. Because we did not quantify carbon storage, we cannot say which traits would rely on stored carbon versus newly acquired carbon in the second year of cane growth.

The potential trade-offs between reproduction and defense we found support our predictions that increased carbon investment to defense (whether by "choice" or "necessity") can restrict allocation toward carbon-demanding reproductive traits. Prickle intensity trading off with ripe fruit number in both species indicates these reproductive structures could rely, to some 
extent, on previously stored rather than newly acquired carbon, given that prickles are produced (primarily) in the year prior to reproduction. That leaf toughness trades off with flower number in blackberry only indicates these two functions may be competing for carbon during the reproductive season as well in the native species, and that there may be a need to defend photosynthetic structures even at the expense of reproductive output during the reproductive bout. These findings are consistent with the aforementioned results of McDowell and Turner (2002), which also found a native Rubus species experiencing greater tension between concurrent resource allocation to vegetative structures (e.g., prickles and leaves) and to reproduction (e.g., flowers and fruits).

It is interesting that blackberry was observed to potentially display five trade-offs, four of which could curtail reproduction, whereas wineberry was observed to display only three tradeoffs, all of which could curtail reproduction. These results suggest that while reproduction is often limited by investments to other life history functions in both species, these limitations may be less severe and/or numerous in wineberry. One possibility is that wineberry has undergone some level of evolutionary change after introduction to limit these life history trade-offs and thus increase the species' competitive advantage over native species given its new set of selective pressures in its novel range, as posited by the EICA hypothesis (Blossey and Nötzold 1995, Joshi and Vrieling 2005). This could help explain why wineberry, on average, has relatively higher reproductive success (in terms of ripe fruits and fruit set) compared to blackberry, though tradeoff and genetic studies would need to be conducted between the invasive population of wineberry and the source population to observe if there are notable genotypic and/or phenotypic differences between the two.

We would recommend that future studies analyze life history function-related traits that 
we were unable to quantify here to more fully characterize these species' reproductive ecology. One trait in particular we'd highlight is trichome density. Björkman and Anderson (1990) found that $R$. bogotensis without trichomes tended to have tougher leaves, suggesting these two characters may play a similar role or may require the same resources and would thus trade off under most circumstance. Our results are broadly consistent with such a possibility in that wineberry possesses trichomes and has, on average, lower leaf toughness values than blackberry, which lacks trichomes. Knowing whether such a relationship exists would help shed light on wineberry's full defensive strategy against insect herbivores specifically, which may be aiding this species' ability to outcompete native congeners and resist natural population regulation in regions like ours where insects are significant herbivores. Such research would also provide insight as to which life history-related traits need to be included in experiments designed to elucidate the possible cause-effect relationships implicit in our results. A clearer understanding of these species' reproductive behaviors could allow researchers to establish cultivation best practices for these species (e.g., establishing treatment thresholds for when insect herbivory is sufficiently likely to reduce yield) as well as curtain expansion of these species in their novel ranges.

We would also recommend that individual rootstocks be studied across multiple years to assess if some herbivory impacts or trade-offs we otherwise did not observe here are instead being distributed across time in these species, making them harder to discern in any given year. Such a project does not appear to have been carried out for this genus to date despite the fact that investments towards growth and reproduction appear to be largely partitioned into separate years in these species. This line of research would allow us to discover if the ecological conditions facing an individual one year affect its behavior in subsequent years, as might be expected for 
conditions such as herbivory and carbon availability that may be relatively stable environmental pressures. We recommend observing first- and second-year cane pairs from the same individual across at least two growing seasons to determine if the behavior of the second-year cane affects the attached first-year cane's reproductive behaviors and outputs the following season. Similarly, herbivory can be observed on a second-year cane to see if there is an impact on the allocation of resources to defense in future canes, indicating defensive induction operating over longer time scales.

\section{Conclusion}

The primary goal of this research was to better understand the reproductive ecology and limitations of Rubus species in our study region. By studying blackberry and wineberry, we discovered potential trade-offs between reproduction and growth, reproduction and defense, and growth and defense, and we also may have identified two potentially inducible defenses in the invasive wineberry. We also identified a few other mechanisms by which wineberry may be succeeding as an invasive in New Jersey, all of which are consistent with the enemy release (Keane and Crawley 2002, Colautti et al. 2004), evolution of increased competitive ability (Blossey and Nötzold 1995), and shifting defense hypotheses (Joshi and Vrieling 2005). We hope our research will serve as a foundation for future studies on the reproductive ecology of this genus more generally.

\section{Acknowledgments}

This project was partially funded and facilitated by the Drew Summer Science Institute (DSSI). The authors wish to thank C. Dabrowski, M. Zielenski, and T. Needham for providing practical help at various stages of the project. 


\section{Author contributions}

BJT designed the experiment. BJT and AWB conducted the field work. BJT carried out laboratory and data analyses and wrote the manuscript with guidance from AWB. Both edited the manuscript and approved of the final language.

\section{Funding}

This research was supported by Drew Summer Science Institute (DSSI).

\section{Data availability}

Data underpinning this work can be made available upon request.

\section{References}

Barton, K.E., and Koricheva J. 2010. The ontogeny of plant defense and herbivory: Characterizing general patterns using meta-analysis. Am. Nat. 175: 481-493. doi: $10.1086 / 650722$.

Bazely, D.R., Myers, J.H., and Burke de Silva K. 1991. The response of numbers of bramble prickles to herbivory and depressed resource availability. Oikos 61: 327-336. doi: 10.2307/3545240.

Beattie, J., Crozier, A., and Duthie, G.G. 2005. Potential health benefits of berries. Curr. Nutr. Food Sci. 1: 71-86. 
Björkman, C., and Anderson, D.B. 1990. Trade-off among antiherbivore defences in a south american blackberry (Rubus bogotensis). Oecologia 85: 247-249. doi: 10.1007/BF00319409.

Blossey, B., and R. Nötzold. 1995. Evolution of increased competitive ability in invasive nonindigenous plants: a hypothesis. J. Ecol. 83:887-889.

Colautti, R.I., A. Ricciardi, I.A. Grigorovich, and H.J. Maclsaac. 2004. Is invasion success explained by the enemy release hypothesis? Ecol. Lett. 7:721-733.

Demetrius, L., and Ziehe, M. 2007. Darwinian fitness. Theor. Pop. Biol. 72: 323-345. doi: 10.1016/j.tpb.2007.05.004.

Feeny, P. 1970. Seasonal changes in oak leaf Tannins and nutrients as a cause of spring feeding by winter moth caterpillars. Ecology 51: 565-581. doi: 10.2307/1934037.

Gibson, D., Bazely, D.R., and Shore, J.S. 1993. Responses of brambles, Rubus vestitus, to herbivory. Oecologia 95: 454-457. doi: 10.1007/BF00321002.

Graham, J., and Brennan, R. 2018. Introduction to the Rubus genus. In Raspberry: Breeding, challenges and advances, 1st ed. Springer Science+Business Media, New York, NY. pp. $1-16$.

Herms, D.A., and Mattson, W.J. 1992. The dilemma of plants: To grow or defend. Q. Rev. Biol. 67: $283-335$

Ito, K., and Sakai, S. 2009. Optimal defense strategy against herbivory in plants: Conditions selecting for induced defense, constitutive defense, and no-defense. J. Theor. Biol. 260: 453-459. doi: 10.1016/j.jtbi.2009.07.002. 
Joshi, J., and K. Vrieling. 2005. The enemy release and EICA hypothesis revisited: incorporating the fundamental difference between specialist and generalist herbivores. Ecol. Lett. 8:704-714.

Karban, R., and Baldwin, I.T. 1997. Induced responses to herbivory. University of Chicago Press, Chicago, IL.

Keane, R.M., and M.J. Crawley. 2002. Exotic plant invasions and the enemy release hypothesis. Trends Ecol. Evol. 17(4):164-170.

Carter, K.A., Liston, A., Bassil, N.V., Alice, L.A., Bushakra, J.M., Sutherland, B.L., Mockler, T.C., Bryant, D.W., and Hummer, K.E. 2019. Target capture sequencing unravels Rubus evolution. Front. Plant Sci. 10: 1615. doi: 10.3389/fpls.2019.01615

Koricheva, J. 2002. Meta-analysis of sources of variation in fitness costs of plant antiherbivore defenses. Ecology 83: 176-190. doi: 10.1890/00129658(2002)083[0176:MAOSOV]2.0.CO;2.

Lailvaux, S.P., and Husak, J.F. 2014. The life history of whole-organism performance. Q. Rev. Biol. 89: 285-318. doi: 10.1086/678567.

Lovett Doust, J. 1989. Plant Reproductive Strategies and Resource Allocation. Trends Ecol. Evol. 4:230-234. https://doi.org/10.1016/0169-5347(89)90166-3

Lowman, M.D. 1984. An assessment of techniques for measuring herbivory: Is rainforest defoliation more intense than we thought? Biotropica 16: 264-268. doi: $10.2307 / 2387934$

Massad, T.J. 2013. Ontogenetic differences of herbivory on woody and herbaceous plants: a meta-analysis demonstrating unique effects of herbivory on the young and the old, the slow and the fast. Oecologia 172: 1-10. doi: 10.1007/s00442-012-2470-1. 
McDowell, S.C.L., and Turner, D.P. 2002. Reproductive effort in invasive and non-invasive Rubus. Oecologia 133: 102-111. doi: 10.1007/s00442-002-1006-5.

Mole, S. 1994. Trade-offs and constraints in plant-herbivore defense theory: A life-history perspective. Oikos 71: 3. doi: 10.2307/3546166.

Muller, O., and Krawinkel, M. 2005. Malnutrition and health in developing countries. Can. Med. Assoc. J. 173: 279-286. doi: 10.1503/cmaj.050342.

Nile, S.H., and Park, S.W. 2014. Edible berries: Bioactive components and their effect on human health. Nutrition 30: 134-144. doi: 10.1016/j.nut.2013.04.007.

Nybom, H., and Schaal, B.A. 1990. DNA “fingerprints" reveal genotypic distributions in natural populations of blackberries and raspberries (Rubus, Rosaceae). Amer. J. Bot. 77: 883888.

Obeso, J.R. 2002. The costs of reproduction in plants. New Phytol. 155: 321-348. doi: 10.1046/j.1469-8137.2002.00477.x.

Pough, F.H. 1989. Organismal performance and darwinian fitness: Approaches and interpretations. Physiol. Zool. 62: 199-236. doi: 10.1086/physzool.62.2.30156169.

R Core Team. 2019. R: A language and environment for statistical computing. Foundation for Statistical Computing, Vienna, Austria.

Sletvold, N., and Ågren, J. 2015. Nonlinear costs of reproduction in a long-lived plant. J. Ecol. 103: 1205-1213. doi: 10.1111/1365-2745.12430.

Stapanian, M.A. 1982. Evolution of fruiting strategies among fleshy-fruited plant species of Eastern Kansas. Ecology 63: 1422-1431. doi: 10.2307/1938869.

Strauss, S.Y., and Agrawal, A.A. 1999. The ecology and evolution of plant tolerance to herbivory. Trends Ecol. Evol. 14: 179-185. doi: 10.1016/S0169-5347(98)01576-6. 
Tontisirin, K., Nantel, G., and Bhattacharjee, L. 2002. Food-based strategies to meet the challenges of micronutrient malnutrition in the developing world. Proc. Nutr. Soc. 61: 243-250. doi: 10.1079/PNS2002155.

Tulchinsky, T.H. 2010. Micronutrient deficiency conditions: Global health issues. Public Health Rev. 32: 243-255. doi: 10.1007/BF03391600.

Turcotte, M.M., Davies, T.J., Thomsen, C.J.M., and Johnson, M.T.J. 2014. Macroecological and macroevolutionary patterns of leaf herbivory across vascular plants. Proc. R. Soc. B. 281: 20140555. doi: 10.1098/rspb.2014.0555.

Wickham, H. 2009. ggplot2: Elegant Graphics for Data Analysis. Springer-Verlag, New York. Williams, V.-R.J., and Sahli, H.F. 2016. A comparison of herbivore damage on three invasive plants and their native congeners: Implications for the enemy release hypothesis. Castanea 81: 128-137. doi: 10.2179/15-069. 
Table 1. Means and standard deviations (SDs) for reproductive, defensive, and growth-related traits as well as average canopy light transmittance and percent leaf loss data from northcentral New Jersey, USA plots containing at least 20 second-year canes (N $=22$ and 36 plots for Rubus allegheniensis and R. phoenicolasius, respectively). Rubus allegheniensis data are presented in the left-hand columns; $R$. phoenicolasius data are presented in the right-hand columns.

\begin{tabular}{|c|c|c|c|c|}
\hline Trait & & Teans & & SDs \\
\hline Flower number & 48.3 & 43.5 & 53.9 & 27.2 \\
\hline Fruit number & 3.5 & 6.6 & 6.3 & 7.9 \\
\hline Fruit set & 0.062 & 0.17 & 0.083 & 0.13 \\
\hline $\begin{array}{l}\text { Fruit dry: wet } \\
\text { mass ratio }\end{array}$ & 0.14 & 0.14 & 0.020 & 0.017 \\
\hline $\begin{array}{l}\text { Stem basal } \\
\text { diameter }(\mathrm{mm})\end{array}$ & 6.10 & 5.65 & 1.81 & 1.23 \\
\hline $\begin{array}{l}\text { Prickle length } \\
(\mathrm{mm})\end{array}$ & 2.2 & 2.7 & 0.78 & 0.47 \\
\hline $\begin{array}{l}\text { Prickle density } \\
\text { (prickles per cm } \\
\text { of stem) }\end{array}$ & 1.8 & 2.2 & 0.72 & 0.64 \\
\hline $\begin{array}{l}\text { Prickle intensity } \\
(\mathrm{mm} \times \text { prickles } / \mathrm{cm}\end{array}$ & 4.0 & 6.0 & 2.4 & 2.4 \\
\hline $\begin{array}{l}\text { Leaf toughness ( } g \\
\text { material) }\end{array}$ & 203.1 & 184.7 & 46.84 & 38.67 \\
\hline Cane length $(\mathrm{cm})$ & 130 & 140 & 42 & 32 \\
\hline $\begin{array}{l}\text { Average leaf size } \\
\left(\mathrm{cm}^{2}\right)\end{array}$ & 76.34 & 67.54 & 25.91 & 17.93 \\
\hline $\begin{array}{l}\text { Canopy light } \\
\text { transmittance }(\% \\
\text { by area) }\end{array}$ & 45.72 & 32.44 & 28.57 & 16.73 \\
\hline $\begin{array}{l}\text { Leaf loss (\% by } \\
\text { area) }\end{array}$ & 3.08 & 1.86 & 3.11 & 3.01 \\
\hline
\end{tabular}


Table 2. Multiple linear regression results assessing for effects of leaf-level herbivory on reproductive, defensive, and growth-related traits in $R$. allegheniensis (blackberry) and R. phoenicolasius (wineberry), including data from plots containing one or both species. The main effect for each model indicates the degree to which the dependent variable changes in response to percent leaf loss. Species was included as an independent variable to assess for differences between species in average dependent variable values separate from those of percent leaf loss. If the "Species Wineberry" term is significant, the beta value indicates how different the average y value would be for wineberry versus blackberry. Models were run under the assumption the two species could also exhibit different responses to herbivory. If the interaction between species and leaf loss was significant, the corresponding beta indicates how the slope of the relationship between the dependent variable and leaf loss would differ for wineberry versus blackberry. When the interaction was not significant, the model was simplified by removing this term. Probability values were adjusted using the false discovery rate and deemed significant (bold) or marginally significant (italics) at $p<0.05$ and $0.05<p<0.1$.

\begin{tabular}{|c|c|c|c|c|c|}
\hline $\begin{array}{l}\text { Dependent } \\
\text { variable }\end{array}$ & $\begin{array}{l}\text { Independent } \\
\text { variable }^{1}\end{array}$ & Term & $\begin{array}{l}\text { Regression } \\
\text { coefficient }(\beta)\end{array}$ & $\begin{array}{l}\text { Test statistic } \\
\text { (t) }\end{array}$ & $p$ value \\
\hline \multicolumn{6}{|l|}{ Flower number } \\
\hline & \multirow[t]{3}{*}{ Percent leaf loss* } & Main effect & -0.0536 & -5.932 & $<0.001$ \\
\hline & & Species - Wineberry & -0.0433 & -0.981 & 0.368 \\
\hline & & Interaction term & 0.0839 & 8.207 & $<0.001$ \\
\hline \multicolumn{6}{|l|}{ Fruit number } \\
\hline & \multirow[t]{3}{*}{ Percent leaf loss* } & Main effect & -0.16 & -3.549 & $<0.001$ \\
\hline & & Species - Wineberry & 0.86 & 5.459 & $<0.001$ \\
\hline & & Interaction term & 0.11 & 2.405 & 0.022 \\
\hline \multicolumn{6}{|l|}{ Fruit set } \\
\hline & \multirow{2}{*}{ Percent leaf loss } & Main effect & -0.011 & -2.275 & 0.035 \\
\hline & & Species - Wineberry & 0.10 & 3.058 & 0.005 \\
\hline \multicolumn{6}{|l|}{$\begin{array}{l}\text { Fruit dry:wet } \\
\text { mass ratio }\end{array}$} \\
\hline & \multirow[t]{2}{*}{ Percent leaf loss } & Main effect & $-2.9 \times 10^{-4}$ & -0.387 & 0.737 \\
\hline & & Species - Wineberry & $-1.8 \times 10^{-3}$ & -0.337 & 0.737 \\
\hline \multicolumn{6}{|l|}{ Average leaf size } \\
\hline & \multirow[t]{3}{*}{ Percent leaf loss* } & Main effect & -0.0313 & -4.931 & $<0.001$ \\
\hline & & Species - Wineberry & -0.329 & -9.946 & $<0.001$ \\
\hline & & Interaction term & 0.0662 & 8.865 & $<0.001$ \\
\hline \multicolumn{6}{|l|}{ Leaf toughness } \\
\hline & \multirow[t]{3}{*}{ Percent leaf loss* } & Main effect & -0.0227 & -5.940 & $<0.001$ \\
\hline & & Species - Wineberry & -0.211 & -10.401 & $<0.001$ \\
\hline & & Interaction term & 0.0382 & 8.150 & $<0.001$ \\
\hline \multicolumn{6}{|l|}{ Prickle intensity } \\
\hline & Percent leaf loss & Main effect & 0.149 & 1.723 & 0.117 \\
\hline & & Species - Wineberry & 2.66 & 4.433 & 0.001 \\
\hline
\end{tabular}


Table 3. Multiple linear regression results assessing for potential trade-offs between reproductive, defensive, and growth-related traits in $R$. allegheniensis (blackberry) and R. phoenicolasius (wineberry), including data from plots containing one or both species. The main effect for each model indicates the degree to which the dependent variable changes in response to the independent variable. Species was included as an independent variable to assess for differences between species in average dependent variable values separate from those of the independent variable. If the "Species - Wineberry" term is significant, the beta indicates how different the average y value would be for wineberry versus blackberry. Models were run under the assumption the two species could exhibit different relationships between the independent and dependent variables. If the interaction between the independent variable and species was significant, the corresponding beta indicates how the slope of the relationship between the dependent variable and independent variable would differ for wineberry versus blackberry. When the interaction was not significant, the model was simplified by removing this term. Probability values were adjusted using the false discovery rate and deemed significant (bold) or marginally significant (italics) at $p<0.05$ and $0.05<p<0.1$, respectively.

\begin{tabular}{|c|c|c|c|c|c|}
\hline Dependent variable & $\begin{array}{l}\text { Independent } \\
\text { variable }^{1}\end{array}$ & Term & $\begin{array}{l}\text { Regression } \\
\text { coefficient }(\beta)\end{array}$ & $\begin{array}{l}\text { Test } \\
\text { statistic (t) }\end{array}$ & $\begin{array}{l}p \\
\text { value }\end{array}$ \\
\hline \multicolumn{6}{|l|}{ Flower number } \\
\hline & \multirow{3}{*}{ Average leaf size* } & Main effect & $4.92 \times 10^{-3}$ & 4.480 & $<0.001$ \\
\hline & & Species - Wineberry & 0.480 & 4.026 & $<0.001$ \\
\hline & & Interaction term & $-5.92 \times 10^{-3}$ & -3.927 & $<0.001$ \\
\hline & \multirow[t]{2}{*}{ Cane length* } & Main effect & 0.012 & 31.142 & $<\mathbf{0 . 0 0 1}$ \\
\hline & & Species - Wineberry & 0.0067 & 0.201 & 0.919 \\
\hline & \multirow[t]{2}{*}{ Basal diameter* } & Main effect & 0.212 & 10.021 & $<0.001$ \\
\hline & & Species - Wineberry & 0.138 & 3.866 & $<0.001$ \\
\hline & \multirow[t]{3}{*}{ Leaf toughness* } & Main effect & $-2.54 \times 10^{-3}$ & -3.872 & $<0.001$ \\
\hline & & Species - Wineberry & -1.06 & -6.521 & $<0.001$ \\
\hline & & Interaction term & $5.43 \times 10^{-3}$ & 6.752 & $<0.001$ \\
\hline & \multirow[t]{3}{*}{ Prickle intensity } & Main effect & -4.8 & -1.791 & 0.117 \\
\hline & & Species - Wineberry & -28 & -1.739 & 0.127 \\
\hline & & Interaction term & 5.8 & 1.892 & 0.101 \\
\hline \multicolumn{6}{|l|}{ Fruit number } \\
\hline & \multirow{2}{*}{ Average leaf size* } & Main effect & -0.020 & -7.862 & $<0.001$ \\
\hline & & Species - Wineberry & 0.77 & 6.314 & $<0.001$ \\
\hline & \multirow[t]{3}{*}{ Cane length* } & Main effect & 0.010 & 5.597 & $<0.001$ \\
\hline & & Species - Wineberry & 0.19 & 0.507 & 0.701 \\
\hline & & Interaction term & 0.0051 & 2.275 & 0.041 \\
\hline & \multirow{2}{*}{ Basal diameter* } & Main effect & 0.18 & 2.349 & 0.034 \\
\hline & & Species - Wineberry & 2.2 & 4.846 & $<0.001$ \\
\hline
\end{tabular}




\begin{tabular}{|c|c|c|c|c|c|}
\hline & & Interaction term & -0.16 & -2.674 & 0.016 \\
\hline & Leaf toughness* & $\begin{array}{l}\text { Main effect } \\
\text { Species - Wineberry } \\
\text { Interaction term }\end{array}$ & $\begin{array}{l}-3.8 \times 10^{-3} \\
-1.1 \\
0.011\end{array}$ & $\begin{array}{l}-1.466 \\
-1.986 \\
3.765\end{array}$ & $\begin{array}{l}0.195 \\
0.078 \\
<\mathbf{0 . 0 0 1}\end{array}$ \\
\hline & Prickle intensity* & $\begin{array}{l}\text { Main effect } \\
\text { Species - Wineberry } \\
\text { Interaction term }\end{array}$ & $\begin{array}{l}-0.10 \\
0.75 \\
0.066\end{array}$ & $\begin{array}{l}-2.838 \\
3.233 \\
1.779\end{array}$ & $\begin{array}{l}\mathbf{0 . 0 1 0} \\
\mathbf{0 . 0 0 3} \\
0.116\end{array}$ \\
\hline \multirow[t]{5}{*}{ Fruit set } & Average leaf size* & $\begin{array}{l}\text { Main effect } \\
\text { Species - Wineberry }\end{array}$ & $\begin{array}{l}-0.016 \\
0.99\end{array}$ & $\begin{array}{l}-1.015 \\
1.206\end{array}$ & $\begin{array}{l}0.393 \\
0.294\end{array}$ \\
\hline & Cane length* & $\begin{array}{l}\text { Main effect } \\
\text { Species - Wineberry }\end{array}$ & $\begin{array}{l}-1.9 \times 10^{-3} \\
1.1\end{array}$ & $\begin{array}{l}-0.226 \\
1.468\end{array}$ & $\begin{array}{l}0.911 \\
0.195\end{array}$ \\
\hline & Basal diameter & $\begin{array}{l}\text { Main effect } \\
\text { Species - Wineberry } \\
\text { Interaction term }\end{array}$ & $\begin{array}{l}-0.032 \\
0.32 \\
-0.039\end{array}$ & $\begin{array}{l}-1.281 \\
2.446 \\
-1.803\end{array}$ & $\begin{array}{l}0.276 \\
\mathbf{0 . 0 3 3} \\
0.117\end{array}$ \\
\hline & Leaf toughness & $\begin{array}{l}\text { Main effect } \\
\text { Species - Wineberry }\end{array}$ & $\begin{array}{l}1.4 \times 10^{-5} \\
0.12\end{array}$ & $\begin{array}{l}0.035 \\
3.287\end{array}$ & $\begin{array}{l}0.972 \\
\mathbf{0 . 0 0 9}\end{array}$ \\
\hline & Prickle intensity & $\begin{array}{l}\text { Main effect } \\
\text { Species - Wineberry }\end{array}$ & $\begin{array}{l}-3.0 \times 10^{-4} \\
0.12\end{array}$ & $\begin{array}{l}-0.036 \\
3.039\end{array}$ & $\begin{array}{l}0.972 \\
\mathbf{0 . 0 0 5}\end{array}$ \\
\hline \multirow{5}{*}{$\begin{array}{l}\text { Fruit dry:wet mass } \\
\text { ratio }\end{array}$} & Average leaf size & $\begin{array}{l}\text { Main effect } \\
\text { Species - Wineberry } \\
\text { Interaction term }\end{array}$ & $\begin{array}{l}-4.7 \times 10^{-4} \\
-0.042 \\
5.0 \times 10^{-4}\end{array}$ & $\begin{array}{l}-2.549 \\
-2.093 \\
2.011\end{array}$ & $\begin{array}{l}\mathbf{0 . 0 2 8} \\
0.071 \\
0.082\end{array}$ \\
\hline & Cane length & $\begin{array}{l}\text { Main effect } \\
\text { Species - Wineberry }\end{array}$ & $\begin{array}{l}-5.2 \times 10^{-5} \\
-7.7 \times 10^{-4}\end{array}$ & $\begin{array}{l}-0.664 \\
-0.138\end{array}$ & $\begin{array}{l}0.614 \\
0.959\end{array}$ \\
\hline & Basal diameter & $\begin{array}{l}\text { Main effect } \\
\text { Species - Wineberry }\end{array}$ & $\begin{array}{l}2.5 \times 10^{-3} \\
5.1 \times 10^{-4}\end{array}$ & $\begin{array}{l}0.693 \\
0.086\end{array}$ & $\begin{array}{l}0.602 \\
0.972\end{array}$ \\
\hline & Leaf toughness & $\begin{array}{l}\text { Main effect } \\
\text { Species - Wineberry }\end{array}$ & $\begin{array}{l}-9.8 \times 10^{-5} \\
-2.6 \times 10^{-3}\end{array}$ & $\begin{array}{l}-1.665 \\
-0.469\end{array}$ & $\begin{array}{l}0.146 \\
0.722\end{array}$ \\
\hline & Prickle intensity & $\begin{array}{l}\text { Main effect } \\
\text { Species - Wineberry }\end{array}$ & $\begin{array}{l}-1.6 \times 10^{-4} \\
-3.9 \times 10^{-4}\end{array}$ & $\begin{array}{l}-0.118 \\
-0.060\end{array}$ & $\begin{array}{l}0.961 \\
0.972\end{array}$ \\
\hline & Cane length* & Main effect & $2.6 \times 10^{-3}$ & 7.425 & $<0.001$ \\
\hline
\end{tabular}




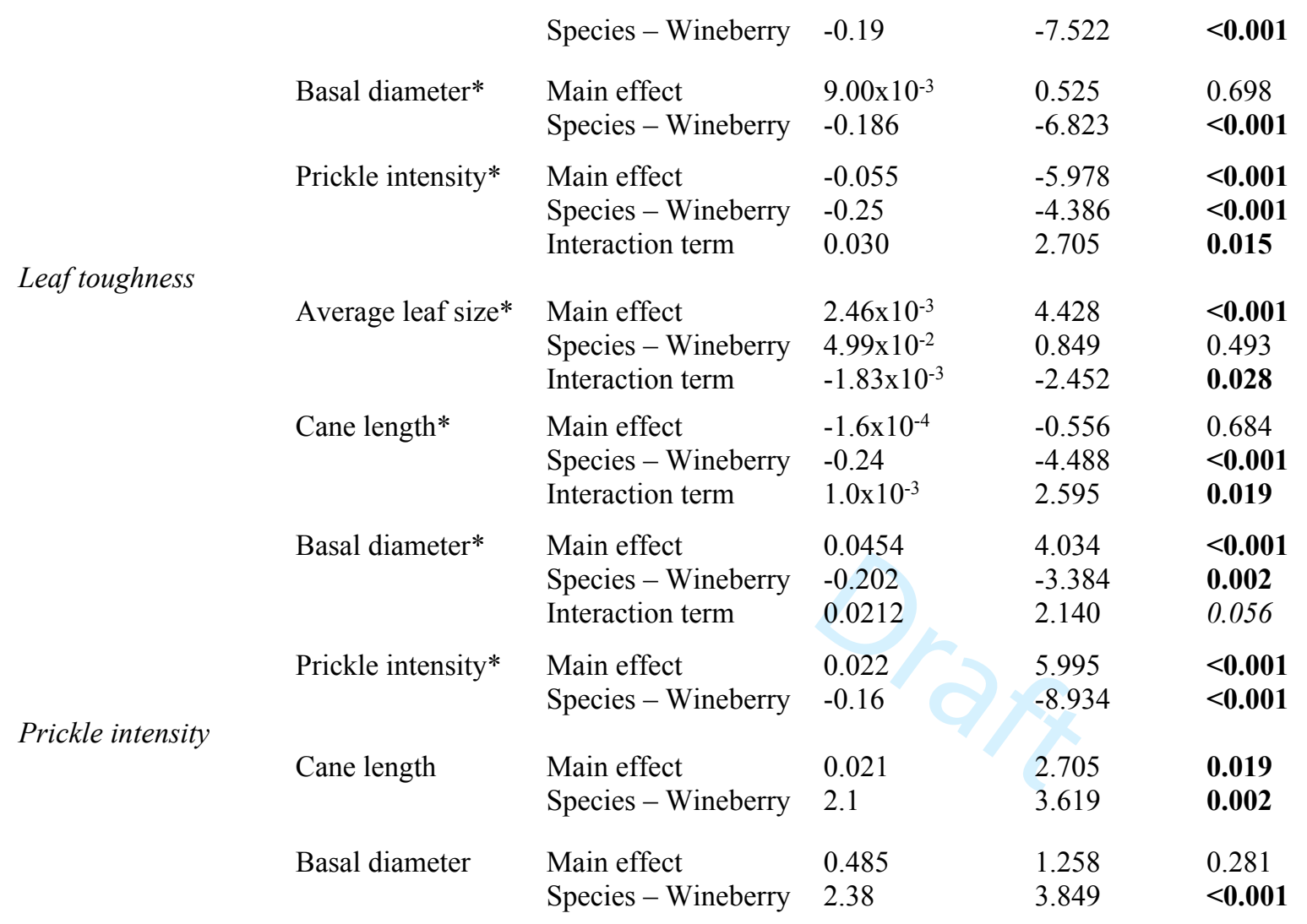


Fig. 1. A Rubus allegheniensis (blackberry) stem (a), two exemplary R. allegheniensis leaves (b and c), and an exemplary R. phoenicolasius (wineberry) leaf and stem (d). The R. allegheniensis stem (a) shows the diagnostic red-purple color and stout prickles that are present across the entire length. The two leaf morphs, a three-leaflet (b) and a five-leaflet (c) morph, can occur on the same cane. The $R$. phoenicolasius (d) stem shows the diagnostic red color and short prickles and hairs present along the entire length and the leaf shape shown (a trifoliate compound leaf with a larger central leaflet that is further away from the others) is typical.

Fig. 2. Images from our canopy cover and leaf area analyses. a) An image of the canopy taken above plot center (left) and then post-analysis in the smartphone application CanopyApp (University of New Hampshire, version 1.0.3; right). The app's software identifies and calculates the percentage of pixels in the picture that contain structures intercepting light, which are those shown in pink. b) An image of a $R$. phoenicolasius (wineberry) leaf (left) and the same image post-analysis in Leaf Area (Adam Campbell, version 1.1.0; right). All non-white pixels are counted by the app's software; thus, the petiole is also included in the calculation of total leaf area. The light-green areas (right) are areas recognized as lost leaf area. The green lines were drawn within the app by hand to fill in missing leaf edge.

Fig. 3. a) Negative linear relationship between a reproductive trait (fruit proportional dry mass; y-axis) and growth (average per-leaf size; $x$-axis), consistent with a physiological trade-off for Rubus allegheniensis (BB; blue, circle) only. The regression coefficient for the slope of the line was statistically significant $(p=0.015)$. The corresponding slope coefficient for $R$. phoenicolasius (WB; pink, triangle) was not significant. b) Negative, non-linear relationship 
between a reproductive trait (number of ripe fruits; $y$-axis) and growth (average leaf size; $x$-axis) in R. allegheniensis (BB; blue, circle) and R. phoenicolasius (WB; pink, triangle), consistent with a physiological trade-off. The coefficients for the slopes of the lines as well as the difference between the species were significant (all $p$ values $<0.001$ ). c) Negative non-linear relationship between a growth trait (average leaf size; y-axis) and a defensive trait (prickle intensity; $\mathrm{x}$-axis) in R. allegheniensis (BB; blue, circle) and R. phoenicolasius (BB; pink, triangle), consistent with a physiological trade-off. The regression coefficients for the slopes of the lines as well as the difference between the species were significant (all $p$ values $<0.01$ ). The solid best-fit lines for $R$. allegheniensis (blue) and $R$. phoenicolasius (pink) are from multiple linear (a) and Poisson $(\mathbf{b}, \mathbf{c})$ regressions accounting for differing light levels and cane lengths (see Methods). The dashed best-fit line (a) is not statistically significant. 
Fig. 1
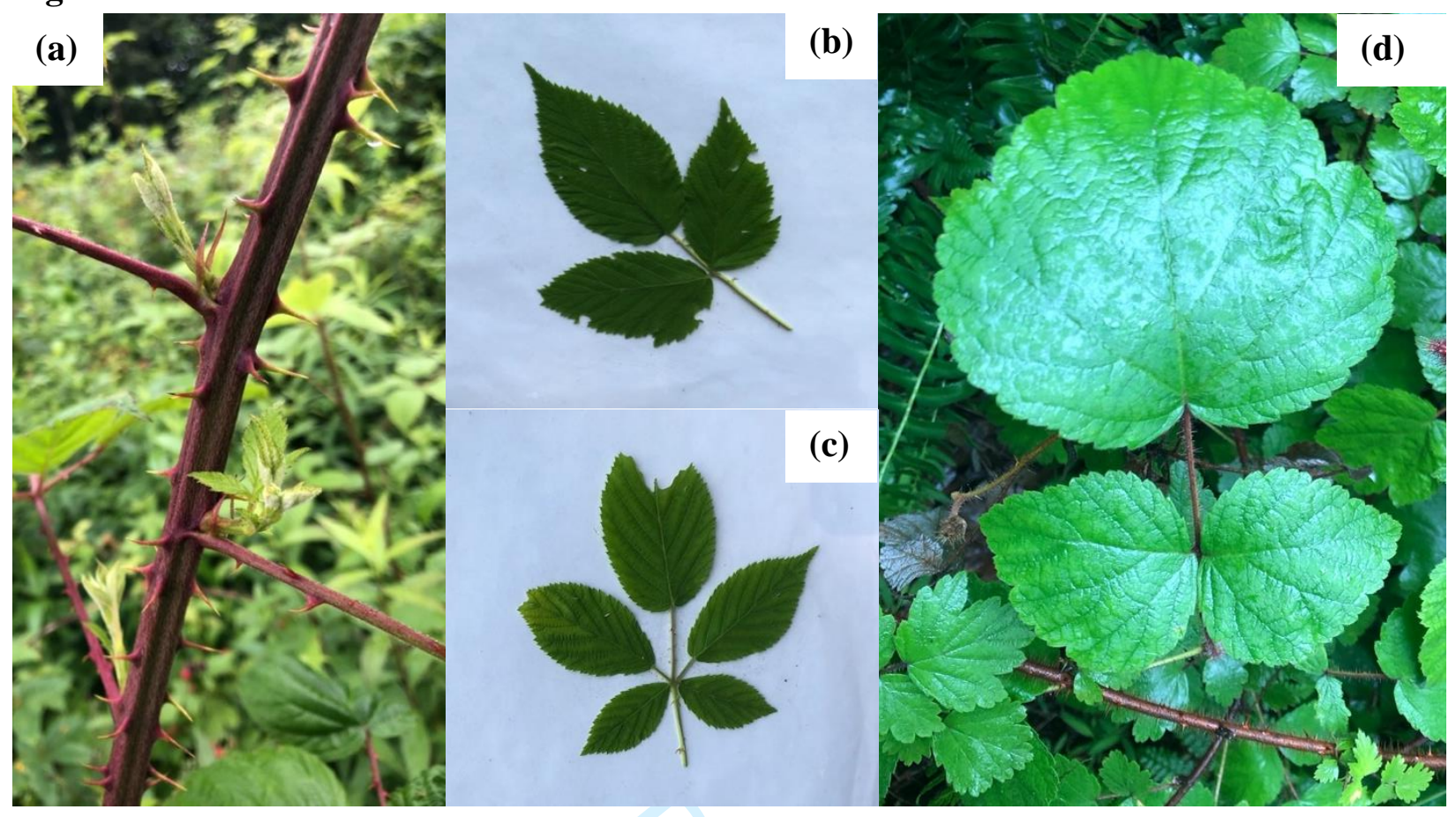
Fig. 2

(a)

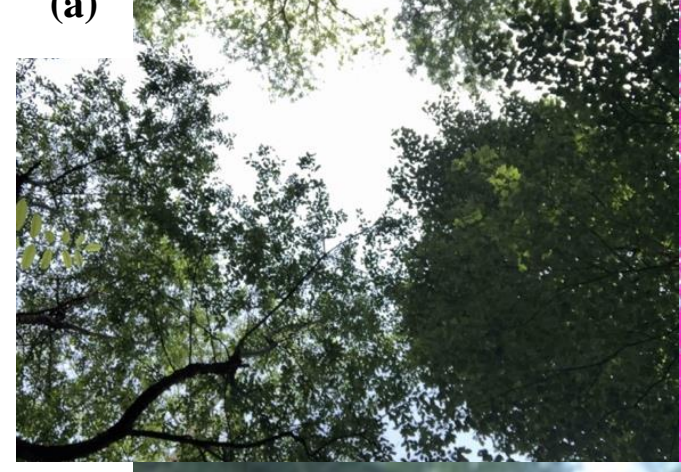
(b)
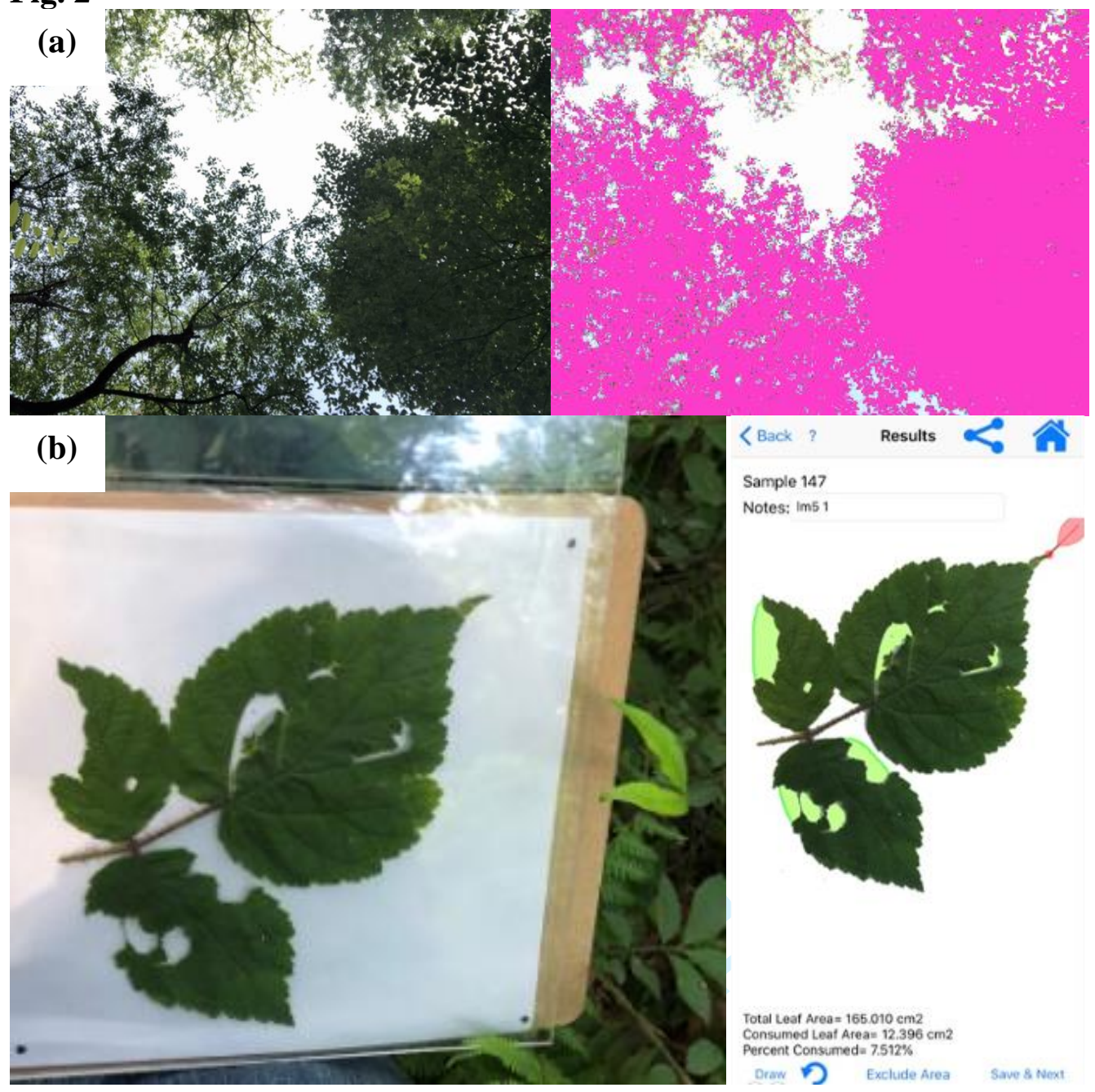

Sample 147

Notes: Im5 1

Total Leaf Area $=165.010 \mathrm{~cm} 2$

Consumed teat Area: $12.396 \mathrm{~cm} 2$

Draw D Exclude Area 
Fig. 3
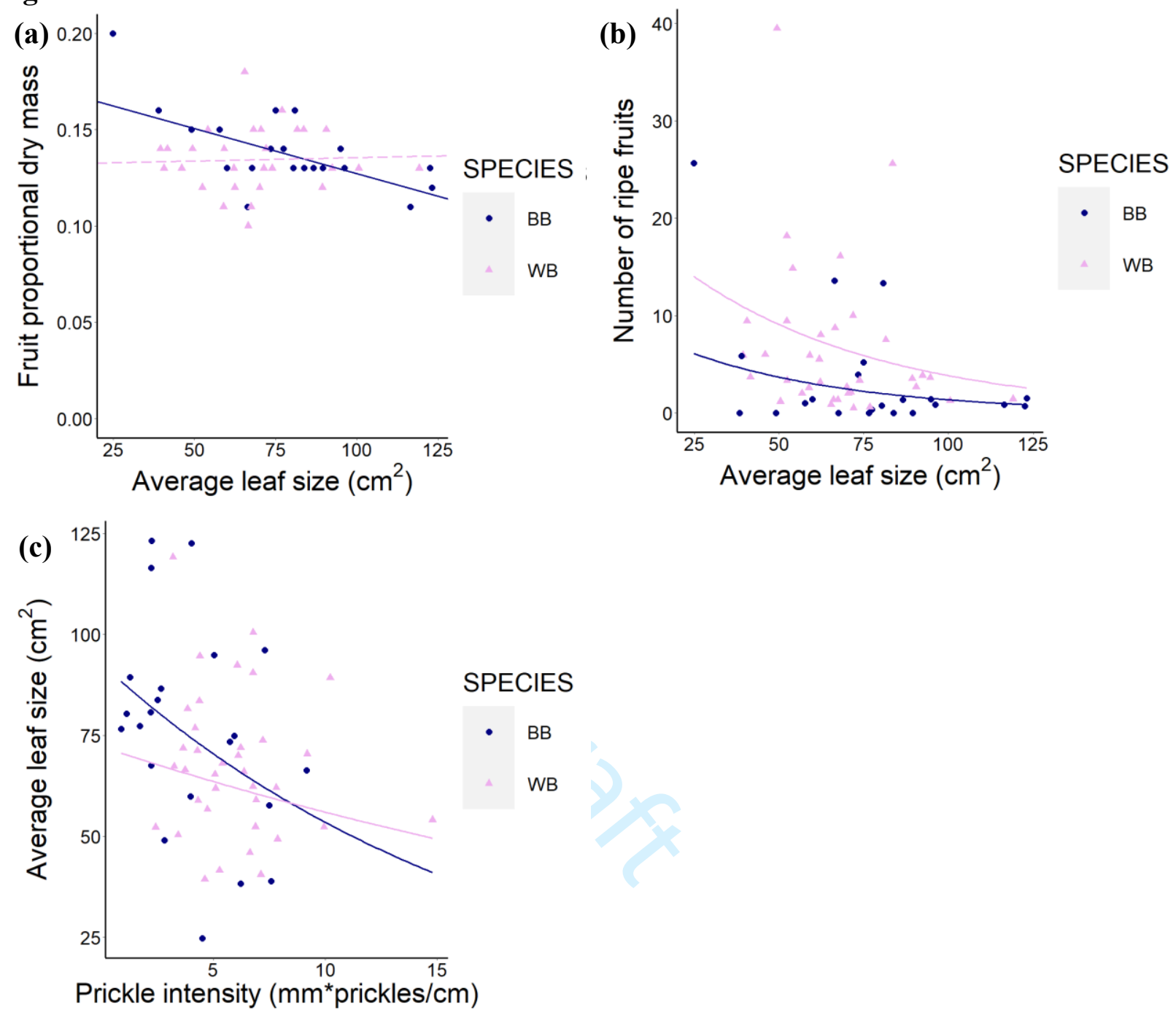